\title{
Increase in interleukin-8 and soluble intercellular adhesion molecule- 1 in bronchoalveolar lavage fluid from premature infants who develop chronic lung disease
}

\author{
Sailesh Kotecha, Barbara Chan, Nazreen Azam, Michael Silverman, Rory J Shaw
}

Department of Paediatrics and Neonatal Medicine, The Royal

Postgraduate Medical School, Hammersmith Hospital, Du Cane

Road, London

W12 0NN

S Kotecha

N Azam

M Silverman

Department of Paediatrics, St Mary's Hospital Medical

School, London

B Chan

Department of Respiratory Medicine R J Shaw

Correspondence to: Dr Sailesh Kotecha.

Accepted 19 October 1994

\begin{abstract}
Interleukin-8 (IL-8), soluble intercellular adhesion molecule-1 (sICAM), elastase and neutrophils were assessed in bronchoalveolar lavage fluid from nine infants who developed chronic lung disease (CLD) after respiratory distress syndrome (RDS), seven who had recovered from RDS, and in four control infants. IL-8, sICAM, elastase and neutrophils in bronchoalveolar lavage fluid were increased in the CLD group, the differences being most pronounced at 10 days of age. When babies with and without CLD were compared at 10 days of age, bronchoalveolar lavage fluid from the babies with CLD had significantly increased IL-8 (114.0 vs $12.7 \mathrm{ng} / \mathrm{ml})$, sICAM (19.0 vs 1.1 $\mu \mathrm{g} / \mathrm{ml})$, elastase $(6.9$ vs $0.9 \mu \mathrm{g} / \mathrm{ml})$ and neutrophils $\left(1.9\right.$ vs $\left.0.4 \times 10^{9} /\right)$. In serum the increased concentration of IL-8 observed at birth in the CLD $(247 \mathrm{pg} / \mathrm{ml})$ and RDS (192 pg/ml) groups decreased over three weeks to the concentrations observed in the controls $(<70 \mathrm{pg} / \mathrm{ml})$. Persistent inflammation could be a major contributory factor in the development of CLD.
\end{abstract}

(Arch Dis Child 1995; 72: F90-F96)

Keywords: chronic lung disease, bronchoalveolar lavage, interleukin-8, intercellular adhesion molecule-1.

Interleukin-8 (IL-8) is a potent neutrophil chemoattractant, ${ }^{78}$ promotes neutrophil degranulation, ${ }^{8-10}$ and induces a weak but rapid respiratory burst in neutrophils. ${ }^{810} \mathrm{IL}-8$ is increased in acute lung injury, including in adult $\operatorname{RDS}^{11-13}$ as well as in idiopathic pulmonary fibrosis. ${ }^{14}$ Furthermore, hyperoxia, to which ventilated preterm infants are frequently exposed, has been shown to result in a four-fold increase in IL-8 gene expression in monocytes when compared with normoxia. ${ }^{15}$

Recruitment of neutrophils to the lung is thought to occur via interactions occurring between adhesion molecules on the surfaces of endothelial cells and neutrophils. ${ }^{1617}$ Intercellular adhesion molecule-1 (ICAM*1, CD54), a member of the immunoglobulin supergene family, mediates migration of neutrophils to the extracellular tissues from postcapillary venules ${ }^{1819}$ via its ligands Mac-1 (CD11b/CD18) and lymphocyte function associated antigen-1, LFA-1 (CD11a/CD18). A soluble form of ICAM-1 (sICAM) has been detected in human serum ${ }^{20}$ and may be useful in monitoring inflammatory disorders. ${ }^{21}$ sICAM is increased in many inflammatory disorders, including idiopathic pulmonary fibrosis, ${ }^{22}$ pulmonary sarcoidosis, ${ }^{22}$ rheumatoid arthritis, ${ }^{23}$ and scleroderma. ${ }^{24}$ sICAM may, therefore, reflect persistent inflammation in these disorders.

Because persistence of neutrophils in the tracheal fluid of preterm infants is associated with CLD, and because IL-8 is a potent neutrophil chemotactic factor, we wanted to ascertain if IL-8 was increased in the bronchoalveolar lavage fluid and serum obtained from preterm infants who developed CLD, compared with preterm infants who recovered from RDS and infants who were ventilated for nonrespiratory reasons. We also measured neutrophils and other elements of neutrophil recruitment and activation, including SICAM and neutrophil elastase. a maximum by 1-2 days of age and decrease to baseline values by the end of the first week of life. ${ }^{23}$ However, in infants who progress to CLD, neutrophilia in tracheal fluid may persist for several weeks. ${ }^{2}$ Similarly, in animal models of CLD persistence of neutrophils is associated with the development of CLD. ${ }^{4}$ Furthermore, evidence for a possible central role for neutrophils is provided by the presence of neutrophil products, such as elastase, in the tracheal fluid of infants with CLD when compared with infants with RDS and controls. ${ }^{256}$

\section{Methods} neonatal intensive care unit at Hammersmith Hospital were recruited for the study. Three groups of infants were studied: (a) infants who required mechanical ventilation for RDS and who subsequently developed CLD - in whom a retrospective diagnosis was made on the basis of oxygen dependency at 28 days of age and
Ventilated infants admitted to the regional 
who had radiological changes of $\mathrm{CLD}^{25}$; (b) infants who received mechanical ventilation for RDS who subsequently recovered and were nursed in air by 28 days of age; (c) control infants who received mechanical ventilation for non-respiratory reasons (including surgery and muscular diseases) and who were nursed in air by 28 days of age. Infants of mothers who had either infection or prolonged rupture of membranes (of greater than 48 hours) were excluded as were infants with sepsis verified by positive blood cultures at birth. Informed consent was obtained from the parents and the study was approved by the local hospital ethics committee.

\section{BRONCHOALVEOLAR LAVAGE}

Each intubated infant receives tracheal suctioning every four to six hours at our centre. Bronchoalveolar lavage was performed at the time of clinically indicated tracheal suctioning using the method described before. ${ }^{26}$ Briefly, with the baby lying supine with the head turned to the left, a FG 5 catheter was advanced through the end porthole of the endotracheal tube until resistance was felt. This method permitted partial ventilation of the infant as disconnection from the ventilator was unnecessary. Two aliquots of $1 \mathrm{ml} / \mathrm{kg}$ (maximum $2 \mathrm{ml}$ ) of saline were instilled. Immediately after instillation after two to three ventilator cycles, a suction pressure of $50 \mathrm{~mm}$ $\mathrm{Hg}$ was applied to the catheter and the returned bronchoalveolar lavage fluid (hereafter also referred to as lavage fluid) collected in a suction 'trap'. Additional oxygen was given to maintain an oxygen saturation, as measured by an oximeter at $90-95 \%$. Infants were lavaged twice weekly for three weeks or until extubation, whichever occurred earlier.

\section{SERUM SAMPLES}

A blood sample $(0.5-1.0 \mathrm{ml})$ was obtained at the time of clinically indicated investigations, and the serum separated and stored at $-70^{\circ} \mathrm{C}$ until further analysis.

\section{CELL COUNTS}

Total lavage fluid returned was recorded and the total cell count estimated with a haemocytometer. A cytospin slide was made from $50 \mu \mathrm{l}$ of lavage fluid centrifuged at $600 \mathrm{rpm}$ for six minutes (Shandon 3, Shandon Products Ltd, Cheshire), fixed in methanol, and stained with Diff-Quick (Merz and Dade AG, Dudingen, Switzerland). A differential cell count was obtained by counting at least 300 cells on each cytospin by the same observer. The remainder of the sample was centrifuged at $400 \times g$, for 10 minutes at room temperature. The supernatant fluid was stored at $-70^{\circ} \mathrm{C}$ until further analysis.

INTERLEUKIN-8 AND SICAM ELISA

IL-8 and sICAM were measured by commercially available enzyme linked immunosorbent assay (ELISA) kits (R\&D Quantikine Human IL-8 D8000, Minneapolis, Minnesota, USA and BBE 1/2 sICAM ELISA version 2, British Biotechnology Products Ltd, Oxford). For the sICAM ELISA an internal control of purified soluble form of recombinant ICAM-1 was provided and was detected within the ranges given in each experiment. Each sample, in each ELISA, was measured in duplicate.

\section{ELASTASE ELISA}

Elastase was measured as a complex with $\alpha_{1}$-antitrypsin. The assay used was a modification of the established neutrophil elastase ELISA $^{27}$ 28: 96-well microtitre plates (Greiner Laboratories Ltd) were coated overnight at room temperature with sheep polyclonal antihuman elastase antibodies (The Binding Site Ltd, Birmingham) diluted 1 in 1000 in $50 \mathrm{mM}$ carbonate bicarbonate buffer (pH 9.6). The plates were washed thoroughly with phosphate buffered saline containing $0.5 \%$ tween 20 (PBS-tween). Non-specific sites were blocked by incubating the plates for 30 minutes in $1 \%$ bovine serum albumin (BSA) (Sigma Chemical Co, St Louis, USA). After washing, the plates were loaded with lavage fluid samples and elastase standards of known concentrations and incubated for two hours at room temperature. After washing with PBStween the second antibody, a sheep polyclonal anti-human $\alpha_{1}$-antitrypsin peroxidase conjugate (The Binding Site Ltd), was diluted 1 in 2000 with PBS-tween and loaded on to the plate and incubated at room temperature for one hour. After washing the plate with PBS-tween $0.2 \mathrm{mg} / \mathrm{ml}$ of the enzyme substrate o-phenylenediamine dihydrochloride (Sigma Chemical Co) and $0.02 \%$ hydrogen peroxide in citric acid buffer ( $\mathrm{pH} 5.0$ ) were added. After 20 minutes of incubation at room temperature in the dark for colour development, the reaction was terminated with $2 \mathrm{M}$ sulphuric acid and absorbance measured at $490 \mathrm{~nm}$ spectroscopically. Concentration of elastase in lavage fluid was estimated against the standards. All samples were measured in duplicate.

EPITHELIAL LINING FLUID

The concentration of serum urea was measured using a urease method in a Technicon RA-XT discretionary analyser (Technicon Instruments Corp, Basingstoke). Urea concentration in lavage fluid was measured on the same analyser at an increased sensitivity whereby a linear dynamic range was achieved over $0.04-6.0 \mathrm{mmol} / 1$. The epithelial lining fluid was estimated by urea dilution: epithelial lining fluid volume (per ml lavage fluid) = lavage fluid urea/serum urea. ${ }^{26}$

\section{STATISTICS}

Mean values for volume of lavage fluid instilled and recovered were compared between groups by one way analysis of variance (ANOVA). For all other experiments median values were used. Neutrophils were expressed as $10^{9} / 1$ of lavage 
Table 1 Median (range) patient data

\begin{tabular}{lllc}
\hline Group & Number & Gestation (weeks) & Birthweight $(g)$ \\
\hline Chronic lung disease & 9 & $25(24-29)$ & $820(570-970)$ \\
Respiratory distress syndrome & 7 & $28(28-33)$ & $1110(840-2130)$ \\
Controls & 4 & $38(31-40)$ & $2690(1380-3240)$ \\
\hline
\end{tabular}

fluid and the concentrations of IL-8, sICAM, and elastase in lavage fluid expressed per $\mathrm{ml}$ of epithelial lining fluid. The non-parametric Kruskal-Wallis test was used to compare multiple groups and the Mann-Whitney U-test was used to compare two groups. A result was considered significant if $p \leqslant 0 \cdot 05$.

\section{Results}

The patient data are shown in table 1 . Twenty babies requiring mechanical ventilation were entered in the study. Of 16 with respiratory failure, nine (five male, four female) subsequently developed CLD and seven (two male, five female) recovered from RDS. Four control infants (two male, two female) received mechanical ventilation for non-respiratory reasons including one for magnetic resonance imaging, two for congenital muscular dystrophy, and one perioperatively for gastroschisis. Mothers who had received antenatal dexamethasone numbered six out of nine among the CLD group, three of seven among the RDS group, and one out of four among the control infants. When the gestational age and birthweight were compared between the groups, a difference was observed between the CLD and RDS groups (gestation $\mathrm{p}<0.01$; birthweight $p<0.05)$, between the CLD and control groups (gestation $p<0.01$; birthweight $\mathrm{p}<0.01$ ), and between the RDS and control groups (gestation $p<0.05$; birthweight $p<0 \cdot 05$ ).

The mean lavage fluid instilled and recovered is shown in table 2 . Significantly less fluid was recovered from the control infants when compared with either the CLD $(p<0.005)$ or $\mathrm{RDS}(\mathrm{p}<0.005)$ groups.

All infants in the CLD and RDS groups had received surfactant (Curosurf, Serono Laboratories), as part of their treatment. In all cases the first bronchoalveolar lavage was performed after the second of two doses of surfactant. Two infants in the CLD group died at the age of 6 and 9 weeks from respiratory failure and necrotising enterocolitis, respectively. On several occasions during the study period, infants were clinically suspected of sepsis but only one infant in the CLD group had a blood culture positive for Pseudomonas aeruginosa, from 16 to 26 days of age.

In infants with CLD the initial neutrophil count of $1.0 \times 10^{9} / 1$ increased to $1.7 \times 10^{9} / 1$ on day 10 , and decreased to $0.6 \times 10^{9} / 1$ at 21 days of age (fig $1 \mathrm{~A}$ ). In contrast, in the infants with RDS the initial neutrophil count of $1.5 \times 10^{9} / 1$ decreased to $0.08 \times 10^{9} / 1$ by 10 days of age. In the control infants the initial neutrophil count was $1 \cdot 2 \times 10^{9} / 1$ but remained between $0 \cdot 4-0 \cdot 6 \times 10^{9} / 1$ thereafter up to 21 days of age.

In infants with CLD the IL-8 concentration in lavage fluid increased from $8.0 \mathrm{ng} / \mathrm{ml}$ on day 1 of age, to $109 \mathrm{ng} / \mathrm{ml}$ by 10 days of age prior to decreasing to $27 \mathrm{ng} / \mathrm{ml}$ by 14 days of age (fig $1 B)$. In the RDS group the initial lavage fluid IL-8 concentration increased from $11 \cdot 1$ to 80 $\mathrm{ng} / \mathrm{ml}$ by 4 days of age, before decreasing to $13.6 \mathrm{ng} / \mathrm{ml}$ thereafter. By comparison, in the control group the initial lavage fluid IL-8 concentration of $44 \mathrm{ng} / \mathrm{ml}$ decreased gradually to $20 \cdot 4 \mathrm{ng} / \mathrm{ml}$ by 17 days of age.

In the CLD group sICAM in lavage fluid was $0.5 \mu \mathrm{g} / \mathrm{ml}$ on day 1 of age, increased to 24 $\mu \mathrm{g} / \mathrm{ml}$ by 7 days of age, and decreased gradually to $5.6 \mu \mathrm{g} / \mathrm{ml}$ by 17 days of age (fig 1C). In infants with RDS SICAM in lavage fluid was $0.4 \mu \mathrm{g} / \mathrm{ml}$ on day 1 , increased to $6.9 \mu \mathrm{g} / \mathrm{ml}$ on day 7 , and decreased to $1.8 \mu \mathrm{g} / \mathrm{ml}$ on day 10 . By contrast, in the control infants the sICAM concentration in lavage fluid remained between 0.6 and $1.6 \mu \mathrm{g} / \mathrm{ml}$ during the first 21 days of life.

The lavage fluid elastase concentration in infants with CLD was $2.3 \mu \mathrm{g} / \mathrm{ml}$ on day 1 , increased to $6.9 \mu \mathrm{g} / \mathrm{ml}$ on day 10 , and gradually decreased to $1.4 \mu \mathrm{g} / \mathrm{ml}$ by day 24 (fig 1D). In the RDS infants elastase in lavage fluid was $2.9 \mu \mathrm{g} / \mathrm{ml}$ on day 1 , increased to a maximum of $9.6 \mu \mathrm{g} / \mathrm{ml}$ on day 4 , and decreased rapidly to $1.0 \mu \mathrm{g} / \mathrm{ml}$ by day 10 . In contrast, in the control infants the initial lavage fluid elastase concentration of $2.3 \mu \mathrm{g} / \mathrm{ml}$ increased to $4.4 \mu \mathrm{g} / \mathrm{ml}$ on day 4 , before decreasing to $0.9 \mu \mathrm{g} / \mathrm{ml}$ on day 10.

The serum IL-8 concentration in the CLD group was $247 \mathrm{pg} / \mathrm{ml}$ on day 1 and gradually decreased to $68 \mathrm{pg} / \mathrm{ml}$ by day 21 (fig 2 ). In the RDS group the serum IL-8 concentration was $192 \mathrm{pg} / \mathrm{ml}$ on day 1 , and, as in the CLD group, decreased gradually to $139 \mathrm{pg} / \mathrm{ml}$ by 10 days of age. By contrast, in the control group the serum IL-8 was persistently between $50-60$ $\mathrm{pg} / \mathrm{ml}$ during the first 21 days of life.

\section{DAY 10 DATA}

As each baby had his or her own time course of increased neutrophils, IL-8, sICAM, and elastase expression in bronchoalveolar lavage fluid, we looked at the cross-sectional data for the above indices for babies breathing oxygen at 28 days of age and those breathing air at 28 days of age to determine if inflammation persisted in those babies who developed CLD when compared with those who did not, and if these indices could be used as predictors for the development of CLD at 10 days of age.

The concentrations of neutrophils, IL-8, sICAM, elastase in lavage fluid and serum IL-8 at 10 days of age, in babies who were subsequently oxygen dependent (CLD) or nursed in air (no CLD) at 28 days of age are shown in

Table 2 Mean (SEM) bronchoalveolar lavage volumes

\begin{tabular}{lccc}
\hline & $C L D$ & $R D S$ & Controls \\
\hline Number & 65 & 16 & 12 \\
$\begin{array}{l}\text { Fluid instilled (ml) } \\
\text { Bronchoalveolar lavage }\end{array}$ & $1.6(0.03)$ & $2 \cdot 1(0.20)$ & $3.5(0.12)$ \\
$\begin{array}{l}\text { fluid recovered (ml) } \\
\begin{array}{c}\text { Fluid recovered (\% of } \\
\text { fluid instilled) }\end{array}\end{array}$ & $1.0(0.04)$ & $1.2(0.07)$ & $1.3(0.17)$ \\
\hline
\end{tabular}

There was a difference in fluid recovered (\%) between the $C L D$ and control groups $(p<0.005)$ and between the RDS and control groups $(p<0.005)$. 

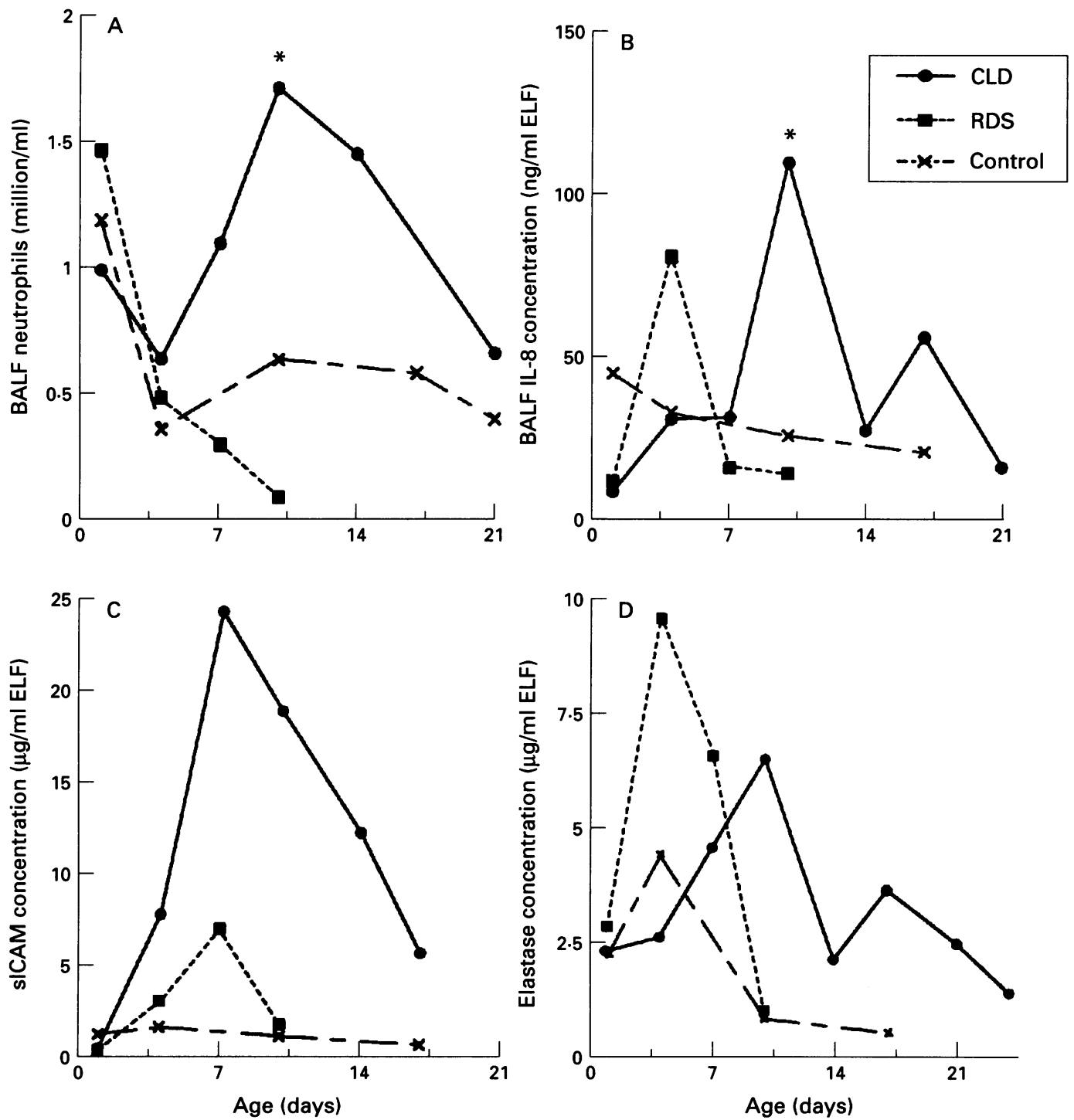

Figure 1 Time course of (A) neutrophil counts, (B) IL-8, (C) sICAM, and (D) elastase concentrations in bronchoalveolar lavage fluid obtained from the CLD, RDS, and control groups. Median values are shown. Chronic lung disease (CLD) $n=9$, respiratory distress syndrome $(R D S) n=7$, and controls $n=4$. ELF=epithelial lining fluid. ${ }^{\star}=p<0.05$ when $C L D$ group was compared with $R D S$ groups.

fig 3. Significant differences between these two groups at 10 days of age were seen for IL-8 $(p<0.01)$, sICAM $(p=0.05)$, elastase $(\mathrm{p}<0.05)$ and neutrophils $(\mathrm{p}<0.05)$ in lavage fluid but not for serum IL-8. When the results at 10 days of age from infants who developed CLD were compared with results from infants who recovered for RDS, a significant increase was noted for IL-8 $(p<0.05)$ (fig 1B) and neutrophils in lavage fluid $(p<0.05)$ (fig $1 A)$ in the CLD group.

\section{Discussion}

We have shown that markers of inflammation, namely interleukin-8, soluble ICAM, neutrophil elastase and neutrophils in bronchoalveolar lavage fluid were all increased in infants who developed CLD when compared with infants with RDS or controls. These differences in neutrophils, IL-8, and sICAM in lavage fluid were most pronounced at 10 days of age when babies who developed CLD were compared with those who did not (fig 3). Furthermore, although the numbers were small, a significant increase was observed for IL-8 and neutrophils in lavage fluid, obtained at 10 days of age, in infants who developed CLD when compared with infants who recovered from RDS (figs $1 \mathrm{~A}$ and $B$ ). This raises the possibility that measurement of these indices at 10 days of age may predict those babies who subsequently develop CLD. This may be of importance in selecting patients who may benefit from treatment such as corticosteroids which are thought to be more beneficial if given early. ${ }^{29}$ Alternatively, measurement of markers of inflammation in lavage fluid at 10 days of age may be used to assess the response to therapeutic manoeuvres instituted during the first few days of life.

In infants with CLD IL-8 in lavage fluid reached maximum concentration by 10 days of age. The importance of IL-8 as a contributor to lung inflammation, is further borne out by the low concentration of $\mathrm{IL}-8$ detected in lavage fluid obtained from control infants and the rapid return to low concentrations by 7-10 days of age in infants with simple RDS. There was no obvious temporal association between neutrophils and IL-8 concentration in lavage 


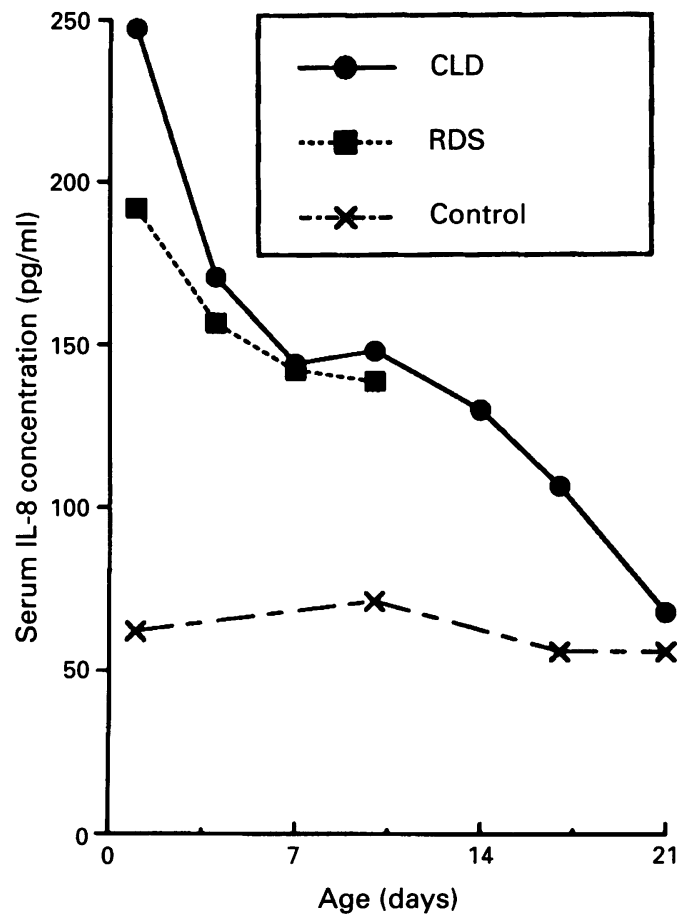

Figure 2 Serum IL-8 concentrations (median value) shown in the CLD, RDS, and control groups.

fluid. To demonstrate such a relation it would probably be necessary to obtain more frequent lavages (perhaps daily) than we had in this study. Such a relation has been demonstrated for idiopathic pulmonary fibrosis ${ }^{14}$ but this is a more slowly progressive disease than CLD where the pulmonary inflammation is much more dynamic and rapidly changing.

IL-8 was increased in other models of acute long injury including the adult $\mathrm{RDS}^{11-13}$ and idiopathic pulmonary fibrosis. ${ }^{14}$ The importance of IL-8 in pulmonary inflammation was demonstrated in reperfusion lung injury in rabbits when lungs were rendered ischaemic by tying the pulmonary arteries for five hours. Anti-IL-8 antibodies given immediately before reperfusion prevented the increase in IL-8 and neutrophil numbers in lavage fluid, and also the disruption of the lung architecture. ${ }^{30} \mathrm{IL}-8$ may have a similar role in infants with CLD as pathologically this disease is also characterised by persistent neutrophil influx ${ }^{2}$ and destruction of lung architecture. ${ }^{31}$

The serum IL-8 results differed from IL-8 results in lavage fluid, in that high concentrations of IL-8 in serum were detected on the first day of life in both CLD and RDS patients. Previous workers have demonstrated higher serum IL-8 concentrations in infants born to mothers with histological evidence of chorioamnionitis than in those with normal placentas. ${ }^{32} 33$ In this study we rigorously excluded infants with infection or those born to mothers with prolonged rupture of membranes or suspected infection. We speculate that the initial high serum IL-8 may reflect perinatal events and may provide a trigger for the early pulmonary inflammation. As the serum IL-8 results were similar in the CLD and RDS groups, it is unlikely that increased serum IL-8 was sufficient to contribute to the persistent changes observed in CLD babies.

In addition to identifying increased IL-8 in lavage fluid, this study provided evidence that the sICAM concentration in lavage fluid was much greater in infants with CLD than in either the RDS or control groups. This difference was also most pronounced by 10 days of age. The recruitment of neutrophils to the lung is thought to occur via a series of complex interactions between the adhesion molecules on the surfaces of endothelial cells and neutrophils. ${ }^{1617}$ Interactions between intercellular adhesion molecule-1 (ICAM-1) and the $\beta_{2^{-}}$ integrins, and Mac-1 (CD11a/CD18) on neutrophils are thought to lead to migration of neutrophils from within postcapillary venules to the extracellular matrix. ${ }^{18}{ }^{19}$ It is difficult to obtain lung biopsy specimens from sick, ventilated preterm babies and, therefore, to determine the expression of ICAM-1 on endothelial and epithelial cells. Thus measurement of sICAM in lavage fluid may provide the best reflection of neutrophil recruitment to the lung of babies who develop CLD.

The results for the IL-8 and sICAM in lavage fluid were supported by the high neutrophil counts in lavage fluid obtained from the CLD group. Neutrophils were high in the first lavage samples we obtained from infants with CLD and RDS. This does not contradict
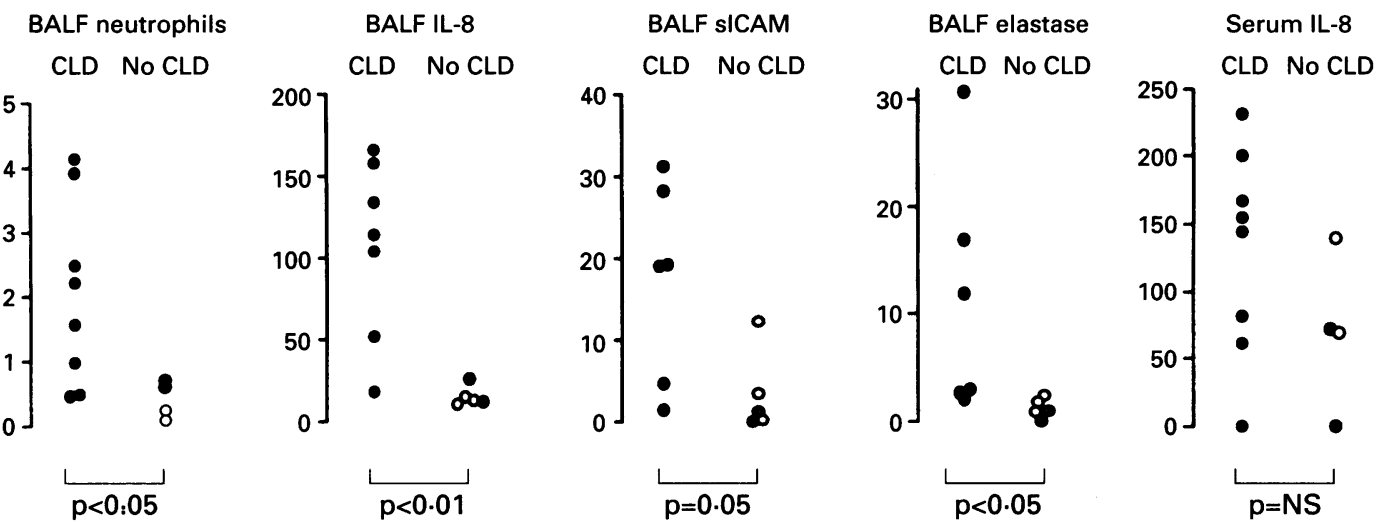

Figure 3 Neutrophils, IL-8, sICAM and elastase concentrations in bronchoalveolar lavage fluid, and IL-8 concentration in serum at 10 days of age in infants with CLD and without CLD (RDS and controls). Concentrations are in million/ml for neutrophils, $\mathrm{ng} / \mathrm{ml}$ for IL-8 in lavage fluid, $\mu \mathrm{g} / \mathrm{ml}$ for sICAM and elastase in lavage fluid, and $\mathrm{pg} / \mathrm{ml}$ for serum $I L-8$. Infants with chronic lung disease (CLD) shown by closed circles, with respiratory distress syndrome (RDS) by open circles, and control infants by shaded circles. 
Ogden's ${ }^{2}$ or Arnon's ${ }^{3}$ observations, that neutrophils are low at birth and increase to a maximum by 1-2 days of age, as we obtained our first lavage sample between 24 and 36 hours of age. In the present study the cell counts were an order of magnitude higher than those obtained by either Ogden ${ }^{2}$ or Arnon, ${ }^{3}$ probably because we did not filter our lavage fluid through sterile gauze, in order to maximise the recovery of cells. We were also concerned that filtering the lavage fluid might result in loss of certain cell types, particularly the inherently adherent macrophages. Mucus was not a problem and in only four from 93 bronchoalveolar lavage samples was a total cell count not possible due to excessive mucus.

Elastase in lavage fluid from babies with CLD was maximal by 10 days of age, before decreasing gradually over the following two weeks (fig 1D). In the RDS group elastase in lavage fluid was maximum at day 4 of age and by day 10 had rapidly decreased to concentrations seen in the control infants. Imbalance between anti-proteinases and proteolytic enzymes in the lung has been documented in the past by several workers in infants who develop CLD when compared with those who do not. ${ }^{256}$ This raises the possibility that the imbalance was minimal or rapidly redressed in those babies with RDS, whereas in infants with CLD it might persist for several weeks.

In this study we were unable to demonstrate any temporal association between clinical indicators of severity, including inspired oxygen concentration, ventilatory requirements including ventilation days required, white cell counts, or C-reactive protein, and the markers of inflammation in lavage fluid. Neither were we able to demonstrate an association between neutrophil counts and IL-8, sICAM, or elastase in lavage fluid. To demonstrate such associations between inflammatory markers it is likely that more frequent lavage and a larger number of infants would be required.

CLD is much more common in those infants with immature lungs - that is, those of extremely low birthweight $(\leqslant 1000 \mathrm{~g})$. It is therefore not surprising that a significant difference was observed in gestation and birthweight between the CLD group and the RDS and control groups. Previous studies examining more mature babies, however, also observed that neutrophilia in lavage fluid was associated with the development of CLD. ${ }^{2}$ It will nevertheless be important, although difficult, to study babies of similar gestation and birthweight who develop CLD or recover from RDS.

The importance of selecting a denominator for epithelial lining fluid estimation was highlighted in this study by the fact that less lavage fluid was recovered from control infants than from either the CLD or RDS groups (table 2). We have estimated the volume of epithelial lining fluid using the urea dilution method. It has been suggested from bronchoalveolar lavage of adults at bronchoscopy that passive diffusion of urea to the lung from blood during the lavage process may underestimate epithelial lining fluid. ${ }^{34}$ However, the dwell time during bronchoalveolar lavage of adults at bronchoscopy is much longer than the few seconds necessary to perform a 1-2 $\mathrm{ml}$ lavage of premature infants. It is thus unlikely that appreciable passive diffusion of urea occurs from the blood to lavage fluid during this time. Our group has already compared the first and second aliquots recovered after bronchoalveolar lavage of preterm ventilated infants and found no difference in the epithelial lining fluid estimated by urea dilution between the two aliquots. ${ }^{26}$

In summary markers of inflammation namely, neutrophils, IL-8 sICAM, and elastase - were increased in bronchoalveolar lavage fluid at 10 days of age in infants subsequently defined as having CLD, on the basis that they were breathing oxygen at 28 days of age, when compared with infants without CLD who were breathing air at 28 days of age (RDS and control groups). By measuring these indices at 10 days of age in lavage fluid, it may be possible to identify babies who subsequently develop CLD and therefore benefit from early treatment with agents such as corticosteroids. More importantly, these measurements at 10 days of age in lavage fluid may be used to assess the response to therapy started during the first few days of life. Our observations might also shed light on the mechanisms underlying this important disease.

$S$ Kotecha has a Training Fellowship from the Medical Research Council. We thank the St Mary's Hospital Standing Research Committee for providing funds to purchase equipment and $\mathrm{Mr}$ Jeremy Beecham, Department of Chemical Pathology, Royal Postgraduate Medical School, for the measurement of urea in bronchoalveolar lavage fluid.

1 Palta M, Gabbert D, Weinstein MR, Peters ME. Multivariate assessment of traditional risk factors for chronic lung disease in very low birth weight neonates. $\mathcal{f}$ Pediatr 1991; 119: 285-92.

2 Ogden BE, Murphy SA, Saunders GC, Pathak D, Johnson JD. Neonatal lung neutrophils and elastase/proteinase inhibitor imbalance. Am Rev Respir Dis 1984; 130: 817-21.

3 Arnon S, Grigg J, Silverman M. Pulmonary inflammatory cells in ventilated preterm infants: effect of surfactant treatment. Arch Dis Child 1993; 69: 44-8.

4 Jackson JC, Chi EY, Wilson CB, Truog WE, Teh EC, Hodson WA. Sequence of inflammatory cell migration into the lung during recovery from hyaline membrane disease in premature newborn monkeys. Am Rev Respir Dis 1987; 135: 937-40.

5 Yoder MC Jr, Chua R, Tepper R. Effect of dexamethasone on pulmonary inflammation and pulmonary function of ventilator- dependent infants with bronchopulmonary ventilator- dependent infants with bronchopul

6 Gerdes JS, Harris MC, Polin RA. Effects of dexamethasone and indomethacin on elastase, alpha 1-proteinase and indomethacin on elastase, alpha l-proteinase inhibitor, and fibronectin in bronchoal

7 Yoshimura T, Matsushima K, Tanaka S, Robinson EA, Appella E, Oppenheim JJ, et al. Purification of a human monocyte-derived neutrophil chemotactic factor that has peptide sequence similarity to other host defense cytokines. Proc Natl Acad Sci USA 1987; 84: 9233-7.

8 Schroder JM, Mrowietz U, Morita E, Christophers E. Purification and partial biochemical characterisation of a human monocyte-derived, neutrophil activating peptide that lacks interleukin 1 activity. F Immunol 1987; 139: 3474-83.

9 Willems J, Joniau M, Cinque S, Van Damme J. Human granulocyte chemotactic peptide (IL-8) as a specific granulocyte chemotactic peptide (IL-8) as a specific monokines. Immunology 1989; 67: 540-2.

10 Peveri P, Walz A, Dewald B, Baggiolini M. A novel neutrophil-activating factor produced by human mononuclear phagocytes. $\mathcal{F}$ Exp Med 1988; 167: 1547-59.

11 Jorens PG, Van Damme J, De Backer W, Bossaert L, DeJongh RF, Herman AG, et al. Interleukin-8 in bronchoalveolar lavage from patients with the adult respiratory distress syndrome and patients at risk of the adult respiratory distress syndrome. Cytokine 1992; 4: 592-7.

12 Miller EJ, Cohen AB, Nagao S, Griffith D, Maunder RJ, Martin TE, et al. Elevated levels of NAP-1/IL-8 are present in the airspaces of patients with the adult respirapresent in the airspaces of patients with the adult respiramortality. Am Rev Respir Dis 1992; 146: 427-32. 
13 Donnelly SC, Strieter RM, Kunkel SA, Walz A, Robertson CR, Carter DC, et al. Interleukin-8 and development of adult respiratory distress syndrome in at-risk groups. Lancet 1993; 341: 643-7.

14 Carre PC, Mortenson RL, King Jr TE, Noble PW, Sable $\mathrm{CL}$, Riches DWH. Increased expression of the interleukin-8 gene by alveolar macrophages in idiopathic pulmonary fibrosis. $f$ Clin Invest 1991; 88: 1802-10.

15 Metinko AP, Kunkel SL, Standiford TJ, Strieter RM. Anoxia-hyperoxia induces monocyte-derived interleukin8. $\mathcal{F C l i n}$ Invest 1992; 90: 791-8.

16 Strieter RM, Lukacs NW, Standiford TJ, Kunkel SL. Cytokine and lung inflammation: mechanisms of neutrophil recruitment to the lung. Thorax 1993; 48: 765-9.

17 Zimmerman GA, Prescott SM, McIntyre TM. Endothelial cell interactions with granulocytes: tethering and signalling molecules. Immunology Today 1993; 13: 93-9.

18 Smith CW, Marlin SD, Rothlein R, Toman C, Anderson DC. Cooperative interactions of LFA-1 and Mac-1 with DC. Cooperative interactions of LFA-1 and Mac-1 with intercellular adhesion molecule-1 in facilitating adherence and transendothelial migration of humar
vitro. $₹$ Clin Invest $1989 ; 83: 2008-17$.

19 Diamond MS, Staunton DE, De Fougerolles AR, Stacker SA, Garcia-Aguilar J, Hibbs ML, et al. ICAM-1 (CD54) a counter-receptor for Mac-1 (CD11b/CD18). f Cell Biol 1990; 111: 3129-39.

20 Rothlein R, Mainolfi EA, Czajkowski M, Marlin SD. A form of circulating ICAM- 1 in human serum. $f$ Immunol 1991; 147: 3788-93.

21 Seth R, Raymond RD, Makgoba MW. Circulating ICAM-1 isoforms: diagnostic prospects for inflammatory and immune disorders. Lancet 1991; 338: 83-4

22 Shijubo N, Imai K, Shigehara K, Honda $Y$, Koba $H$, Tsujisaki M, et al. Soluble intercellular adhesion molecule-1 (ICAM-1) in sera and bronchoalveolar lavage of patients with idiopathic fibrosis and pulmonary sarcoidosis. Clin Exp Immul 1994; 95: 156-61.

23 Mason JC, Kapahi P, Haskard DO. Detection of increased level of circulating intercellular adhesion molecule-1 in some patients with rheumatoid arthritis but not in patients with systemic lupus erythematosus. Lack of correlation with levels of circulating vascular cell adhesion molecule1. Arthritis Rheum 1993; 36: 519-27.
24 Sfikakis PP, Tesar J, Baraf H, Lipnick R, Klipple G, Tsokos GC. Circulating intercellular adhesion molecule-1 in patients with systemic sclerosis. Clin Immunopathol 1993; 68: 88-92

25 Bancalari E, Abdenour GE, Feller R, Gannon J. Bronchopulmonary dysplasia: clinical presentation f Pediatr 1979; 95: 819-23.

26 Grigg J, Arnon S, Silverman M. Fractional processing of sequential bronchoalveolar lavage fluid from intubated babies. Eur Respir f 1992; 5: 727-32.

27 Ochnio J, Abboud RT, Smyrnis EM, Johal SS. A sensitive double-sandwich ELISA for neutrophil elastase. $A m$ Rev Respir Dis 1991; 143: 61-5.

28 Fink PC, Suin de Boutemand C, Haeckel R. Measurement of leucocyte elastase $/ \alpha_{1}$ proteinase-inhibitor complex using a homogeneous and a heterogeneous enzymeimmunoassay. $¥$ Clin Chem Clin Biochem 1989; 27: 869-71.

29 Yeh TF, Torre JA, Rastogi A, Anyebuno MA, Pildes RS Early postnatal dexamethasone therapy in premature infants with severe respiratory distress syndrome: double blind controlled study. $\mathcal{f}$ Pediatr 1990; 117 273-82.

30 Sekido N, Mukaida N, Harada A, Nakanishi I, Watanabe Y, Matsushima K. Prevention of lung perfusion injury in rabbits by a monoclonal antibody against interleukin- 8 . Nature 1993; 365: 654-7.

31 Askin F. Respiratory tract disorders of the fetus and neonate. In: Wigglesworth JS, Singer DB, eds. Textbook of fetal and perinatal pathology. Cambridge, MA: Blackwell Scientific Publications, 1991: 666-70.

32 Romero R, Ceska M, Avila C, Mazor M, Behnke E, Lindley I. Neutrophil attractant/activating peptide-1/interleukin-8 in term and preterm parturition. Am $f$ Obstet Gynecol in term and preterm

33 Shimoya K, Matsuzaki N, Taniguchi T, Jo T, Saji F, Kirajima $\mathrm{H}$, et al. Interleukin-8 in cord sera: a sensitive and specific marker for the detection of preterm chorioamnionitis. F Infect Dis 1992; 165: 957-60.

34 Ward C, Duddridge J, Fenwick J, Williams S, Gardiner PV Hendrick DJ, et al. The origin of water and urea sampled at bronchoalveolar lavage in asthmatic and control subjects. Am Rev Respir Dis 1992; 146: 444-7. 